\title{
Sun exposure and melanoma prognostic factors
}

\author{
SARA GANDINI $^{1}$, MAURIZIO MONTELLA ${ }^{2}$, FABRIZIO AYALA $^{3}$, LUCIA BENEDETTO $^{3}$, \\ CARLO RICCARDO ROSSI ${ }^{4,5}$, ANTONELLA VECCHIATO ${ }^{5}$, MARIA TERESA CORRADIN ${ }^{6}$, \\ VINCENZO DE GIORGI $^{7}$, PAOLA QUEIROLO ${ }^{8}$, GUIDO ZANNETTI $^{9}$, GIUSEPPE GIUDICE ${ }^{10}$, \\ GIOVANNI BORRONI ${ }^{11}$, ROSACHIARA FORCIGNANÒ ${ }^{12}$, KETTY PERIS $^{13}$, GIULIO TOSTI $^{14}$, \\ ALESSANDRO TESTORI $^{14}$, GIUSTO TREVISAN ${ }^{15}$, FRANCESCO SPAGNOLO ${ }^{16}$ and PAOLO A. ASCIERTO ${ }^{3}$ \\ CLINICAL NATIONAL MELANOMA REGISTRY GROUP
}

${ }^{1}$ Division of Epidemiology and Biostatistics, European Institute of Oncology, Milan I-20146; ${ }^{2}$ Department of Epidemiology;

${ }^{3}$ Unit of Medical Oncology and Innovative Therapies, National Cancer Institute 'G. Pascale' Foundation,

Naples I-80131; ${ }^{4}$ Department of Surgical Oncological and Gastroenterological Sciences, Padua University, Padua I-35122; ${ }^{5}$ Melanoma and Sarcoma Unit, Veneto Oncological Institute for Research and Treatment, Padua I-35128;

${ }^{6}$ Department of Dermatology, Society of Clinical Oncology Santa Maria Degli Angeli Oncological Hospital,

Pordenone I-33170; ${ }^{7}$ Department of Dermatology, Tuscan Orthopaedic Institute Hospital 'Palagi', University of Florence,

Florence I-50125; ${ }^{8}$ Department of Medical Oncology, Company University Hospital San Martino,

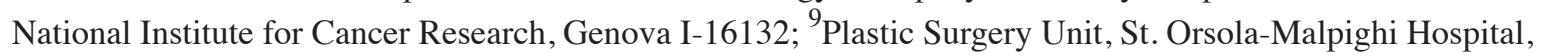

Bologna I-40138; ${ }^{10}$ Department of Plastic and Reconstructive Surgery, University of Bari,

Bari I-70121; ${ }^{11}$ Dermatalogical Clinic, Institute for Research and Treatment San Matteo Hospital, Pavia I-27100;

${ }^{12}$ Oncological Unit, Vito Fazzi Hospital, Lecce I-73100; ${ }^{13}$ Dermatological Institute, Catholic University of America,

Rome I-00153; ${ }^{14}$ Melanoma Unit, European Institute of Oncology, Milan I-20146; ${ }^{15}$ Dermatalogical Clinic,

Maggiore Hospital, Trieste I-34125; ${ }^{16}$ Department of Plastic and Reconstructive Surgery,

Company University Hospital San Martino, National Institute for Cancer Research, Genova I-16132, Italy

Received December 2, 2014; Accepted December 8, 2015

DOI: $10.3892 / 01.2016 .4292$

\begin{abstract}
Previous studies have reported an association between sun exposure and the increased survival of patients with cutaneous melanoma (CM). The present study analyzed the association between ultraviolet (UV) light exposure and various prognostic factors in the Italian Clinical National Melanoma Registry. Clinical and sociodemographic features were collected, as well as information concerning sunbed exposure and holidays with sun exposure. Analyses were performed to investigate the association between exposure to UV and melanoma prognostic factors. Between December 2010 and December 2013, information was obtained on 2,738 melanoma patients from 38 geographically representative Italian sites. A total of $49 \%$ of the patients were $>55$ years old, $51 \%$ were men, $50 \%$ lived in the north of Italy and $57 \%$ possessed a high level of education (at least high school). A
\end{abstract}

Correspondence to: Dr Maurizio Montella, Department of Epidemiology, National Cancer Institute 'G. Pascale' Foundation, 52 Mariano Semmola Street, Naples I-80131, Italy

E-mail:m.montella@istitutotumori.na.it

Key words: sun exposure, melanoma, prognosis, Breslow thickness, ulceration, sunbed total of 8 patients had a family history of melanoma and $56 \%$ had a fair phenotype (Fitzpatrick skin type I or II). Of the total patients, $29 \%$ had been diagnosed with melanoma by a dermatologist; $29 \%$ of patients presented with a very thick melanoma (Breslow thickness, $>2 \mathrm{~mm}$ ) and $25 \%$ with an ulcerated melanoma. In total, $1 \%$ of patients had distant metastases and $13 \%$ exhibited lymph node involvement. Holidays with sun exposure 5 years prior to CM diagnosis were significantly associated with positive prognostic factors, including lower Breslow thickness $(\mathrm{P}<0.001)$ and absence of ulceration $(\mathrm{P}=0.009)$, following multiple adjustments for factors such as sociodemographic status, speciality of doctor performing the diagnosis and season of diagnosis. Sunbed exposure and sun exposure during peak hours of sunlight were not significantly associated with Breslow thickness and ulceration. Holidays with sun exposure were associated with favorable $\mathrm{CM}$ prognostic factors, whereas no association was identified between sunbed use and sun exposure during peak hours of sunlight with favorable CM prognostic factors. However, the results of the present study do not prove a direct causal effect of sun exposure on melanoma prognosis, as additional confounding factors, including vitamin D serum levels, may have a role.

\section{Introduction}

Approximately 200,000 patients are diagnosed with cutaneous melanoma (CM) annually worldwide, and 46,000 succumb to 
the disease (1). The incidence of CM has steadily increased over the last 50 years in the majority of fair-skinned populations (2-5), even though the great majority of the increase in melanoma incidence has been suggested to be due to an increase in the diagnosis of thin lesions that possess an excellent prognosis $(6,7)$, and a previous study demonstrated a change in the trend suggesting that the most recent generation are at a lower risk of developing melanoma (8).

Mortality rates have not been observed to parallel incidence rates. In Australia, mortality rates peaked in 1985 and then stopped rising (9), while in the USA, between 1992 and 2006 , mortality rates increased only in patients $>65$ years old (10). In Europe, melanoma mortality doubled in men, but remained unchanged in women (11).

The discrepancy between incidence and mortality trends has been discussed and certain studies attribute this trend to the detection of melanoma at earlier stages in women compared with men (12), or in general to the over-diagnosis of thin slow melanoma. Other studies have suggested that part of the melanoma epidemic is comprised of non-life-threatening melanomas that may be promoted by sun exposure (13).

Solar radiation is an established skin carcinogen $(14,15)$, however, sun exposure is additionally the primary source of vitamin $\mathrm{D}$, and it has been demonstrated that vitamin $\mathrm{D}$ is associated with a reduced risk of cancer and overall mortality (16-19). Thus, the main cause of melanoma may be intentional ultraviolet (UV) exposure, as a continuous pattern of sun exposure may not be significant risk factor, as it has been shown in a previous meta-analysis (14). However, intermittent sun exposure and sunbed use are consistently associated with an increased risk of melanoma (20).

In a cohort of Swedish women, overall mortality was significantly reduced by $30 \%$ among those who had taken vacations featuring exposure to sun more than once a year over 3 decades. Conversely, solarium use one or more times per month for at least a decade significantly increased the risk of all causes of mortality and cancer-associated mortality compared with those who never used solaria (21). Consistently, in a previous study of an Italian patient cohort, holidays with exposure to the sun prior to diagnosis were associated with thinner melanomas in women and reduced rates of relapse in the two genders (22).

The present study aimed to confirm previously observed results in a larger patient cohort, investigating the primary prognostic factors of melanoma in association with sun and artificial light exposure, and adjusting for possible confounders, including socioeconomic factors, history of non-melanoma skin cancer, body site, specialization of diagnosing doctors and season of diagnosis.

\section{Materials and methods}

Patients and data collection. Since December 2010, the present hospital-based multicenter study of melanoma cases has been ongoing in Italy. Patients exhibiting a histologically confirmed diagnosis of primary CM were recruited from Italian institutions (hospitals and university settings, including dermatological, surgical and oncological units) between December 2010 and December 2013. Following the provision of written informed consent, patients were enrolled in the study and all data expected from the study plan was collected via an electronic Case Report Form (eCRF), which was developed by Clinical Research Technology S.r.l. (Salerno, Italy) on its clinical platform 'eClinical'. 'eClinical' assigned an identification (ID) number to all screened patients.

The acquisition and collection of clinical data were achieved through utilizing central web based systems (http://imi.cr-technology.com/cnmr/). eClinical software was compliant with Computer System Validation (US Food and Drug Administration-21 CFR Part 11: Electronic Records; Electronic Signatures; http://www.accessdata.fda.gov/scripts/ cdrh/cfdocs/cfcfr/CFRSearch.cfm?CFRPart=11) (23). The eCRF layout was designed to collect the data specified by the study protocol. Among other features, eClinical assigned a unique and secure User ID/password combination for each clinical research team member, managed queries and developed descriptive statistics. The quality of the electronic data was verified against the source documents via onsite monitoring visits periodically undertaken during the study. Patients interviewed at the initial diagnosis of melanoma were considered as incident cases.

Study variables. A self-administered questionnaire, which collected information on sociodemographic variables (age at melanoma diagnosis, gender and level of education), body mass index (BMI), host factors (phenotype), UV exposure (holidays with sun exposure in the previous 5 years), sun exposure during peak hours of sunlight (11:00 a.m. to 1:00 p.m.) in the previous 2 years, sunbed use (prior to the age of 30), geographical residence, season of diagnosis and site of melanoma (head and neck, trunk, upper limb and lower limb). Skin sensitivity to UV was measured using the Fitzpatrick classification, with a six-level scale ranging from subjects who always tan and never burn to subjects who always burn when exposed to sun (24).

Statistical analysis. Associations between categorical variables at baseline and Breslow thickness were evaluated using non-parametric median two-sample tests that evaluated differences in median Breslow thickness. Associations between categorical variables and frequencies of patients with holidays with sun exposure were evaluated using the $\chi^{2}$ test or Fisher's exact test, as appropriate.

Multivariate analyses were performed with Breslow thickness as the response variable, and also to investigate variables associated with sunbed use and holidays with sun exposure. Information on lesion thickness was investigated and patients were grouped into two categories, thin and thick melanoma (Breslow thickness, $\leq 1.00$ and $>1.00 \mathrm{~mm}$, respectively), considering very thick melanoma (Breslow thickness, $>2.00 \mathrm{~mm}$ ) and additionally evaluating Breslow thickness as a continuous measure. Multivariate logistic models were utilized to evaluate the associations for thick and very thick melanoma. Multivariate random effects models, with center considered as a random factor, were introduced, transforming Breslow thickness in order to achieve a normal distribution of residuals. All possible confounding factors, including age, gender, educational and professional level, phenotype, residence, season of diagnosis and speciality of diagnosing doctor were evaluated in the multivariate models. 
Table I. Odds ratio and $95 \%$ confidence interval for use of sunbeds and holidays with sun exposure from the multivariate model.

A, Odds ratio and $95 \%$ confidence interval for use of sunbeds from the multivariate model

\begin{tabular}{|c|c|c|c|c|}
\hline Variable & Category & Odds ratio & $95 \%$ confidence interval & P-value ${ }^{a}$ \\
\hline Age, years & $\geq 55$ vs. $<55$ & 0.29 & $0.22-0.38$ & $<0.0001$ \\
\hline Gender & Men vs. women & 0.44 & $0.34-0.57$ & $<0.0001$ \\
\hline Body mass index & $\geq 25$ vs. $<25$ & 0.64 & $0.50-0.82$ & 0.0004 \\
\hline $\mathrm{SES}^{\mathrm{b}}$ & High vs. low & 1.20 & $1.01-1.32$ & 0.0003 \\
\hline Sun exposure & Yes vs. no & 2.19 & $1.64-2.93$ & $<0.0001$ \\
\hline
\end{tabular}

B, Odds ratio and $95 \%$ confidence interval for holidays with sun exposure from the multivariate model

\begin{tabular}{|c|c|c|c|c|}
\hline Variable & Category & Odds ratio & $95 \%$ confidence interval & P-value ${ }^{c}$ \\
\hline Age, years & $\geq 55$ vs. $<55$ & 0.45 & $0.37-0.53$ & $<0.0001$ \\
\hline $\mathrm{SES}^{\mathrm{b}}$ & High vs. low & 1.36 & $1.27-1.46$ & $<0.0001$ \\
\hline \multirow[t]{2}{*}{ Residence } & North vs. south & 0.75 & $0.62-0.89$ & $<0.0001$ \\
\hline & Centre vs. south & 1.54 & $1.13-2.10$ & $<0.0001$ \\
\hline Sunbed use & Yes vs. no & 2.25 & $1.69-2.99$ & $<0.0001$ \\
\hline
\end{tabular}

${ }^{a} \mathrm{P}$-values from multivariate logistic model with sunbed use as the response variable. ${ }^{\mathrm{b}}$ Socioeconomic status (SES) score, including educational and professional level. 'P-values from multivariable logistic model with sun exposure as response variable.

All analyses were performed with SAS software version 9.2 (SAS Institute, Cary, NC, USA) and R software, version 2.12.2 (http://www.r-project.org). All reported P-values were two-sided $(\mathrm{P}<0.05)$.

\section{Results}

Characteristics of the patient cohort. Patients from 38 centers were included in the present study: $50 \%$ from the north, $11 \%$ from the center and $40 \%$ from the south of Italy and its islands. A total of $33 \%$ of the centers were dermatology units. For the present analysis, patients exhibiting CM with information on melanoma thickness were selected. From 3,111 patients, the following cases were excluded: Acral lentiginous melanoma $(\mathrm{n}=12 ; 0.4 \%)$, mucosal lentiginous melanoma $(\mathrm{n}=14 ; 0.5 \%)$, vulvar and anorectal melanoma $(\mathrm{n}=18 ; 0.6 \%)$, in situ melanoma $(n=41 ; 1 \%)$ and retrospective melanoma $(n=288 ; 9 \%)$. Following exclusion, a final cohort of 2,738 patients diagnosed between December 2010 and December 2013 remained, and $99 \%$ of these patients exhibited first primary melanoma.

The median patient age was 55 years (interquartile range, 43-68 years). In total, $51 \%(n=1,398)$ of patients were men and $57 \%(n=1,553)$ had a high level of education (at least high school). Furthermore, 9\% $(n=234)$ of the patients had melanoma familiarity and $56 \%(n=1,527)$ exhibited a fair phenotype (Fitzpatrick skin type I or II). A total of $50 \%$ $(n=1,375)$ of patients exhibited a thin melanoma (Breslow thickness, $\leq 1 \mathrm{~mm})$, and $29 \%$ percent $(\mathrm{n}=806)$ had a very thick melanoma (Breslow thickness, $>2 \mathrm{~mm}$ ). Additionally, 25\% $(n=694)$ of patients had ulcerated melanoma, and 1\% $(n=34)$ exhibited distant metastases, with lymph node involvement in $13 \%(n=357)$ of patients. A total of $28 \%(n=774)$ of patients were diagnosed by a dermatologist and significantly $(\mathrm{P}<0.001)$ higher numbers of thin melanoma cases were diagnosed by dermatologists $(53 \%)$ compared with other types of medical doctor $(46 \%)$.

A number of factors are associated with sunbed use and holidays with sun exposure. Sunbed use was significantly associated with age $(\mathrm{P}<0.0001)$, gender $(\mathrm{P}<0.0001), \mathrm{BMI}$ $(\mathrm{P}=0.004)$, social economic status $(\mathrm{SES} ; \mathrm{P}=0.0003)$ and holidays with sun exposure $(\mathrm{P}<0.0001)$, with an increased prevalence among younger women $(<55$ years) with low BMI $(<25)$ (Table I). However, holidays with sun exposure were associated with SES $(\mathrm{P}<0.0001)$ and residence $(\mathrm{P}<0.0001)$, but not with gender or BMI (Table I).

Table II presents the associations between patient characteristics and holidays with sun exposure. Thick melanoma was less frequent among patients taking holidays with sun exposure compared with those who did not take holidays with sun exposure (57 vs. $46 \%$; $\mathrm{P}<0.0001)$. Patients with a history of holidays with sun exposure in the 5 years prior to diagnosis were younger (patients $\geq 55$ years old demonstrated 39 vs. $66 \%$, for holidays with sun exposure vs. holidays with no sun exposure; $\mathrm{P}<0.0001)$, had a higher educational and professional level $(\mathrm{P}<0.0001)$, and possessed a fair phenotype (54 vs. 61\%, for holidays with sun exposure vs. holidays with no sun exposure; $\mathrm{P}=0.004$ ) and low BMI (49 vs. 59\% BMI $\geq 25$, for holidays with sun exposure vs. holidays with no sun exposure; $\mathrm{P}<0.0001)$.

A number of factors are associated with Breslow thickness and ulceration. Table III presents sociodemographic characteristics that were identified to be significantly associated with Breslow thickness in a multivariate random effects model. As expected, men, patients $>55$ years old and patients with a low education had a significantly greater Breslow 


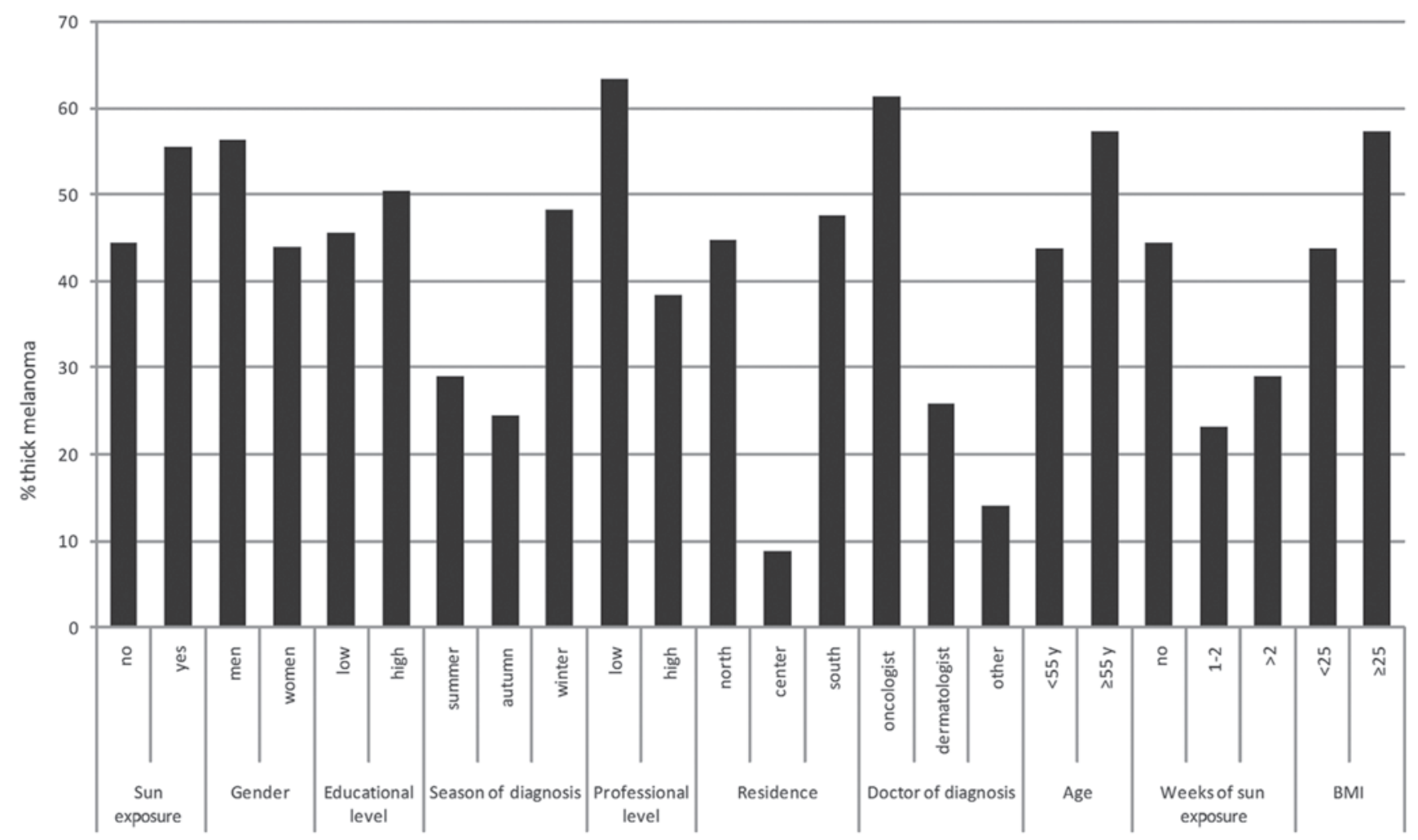

Figure 1. Histogram of proportions of thick melanoma (Breslow thickness, $>1.00 \mathrm{~mm}$ ). BMI, body mass index; Y, years.

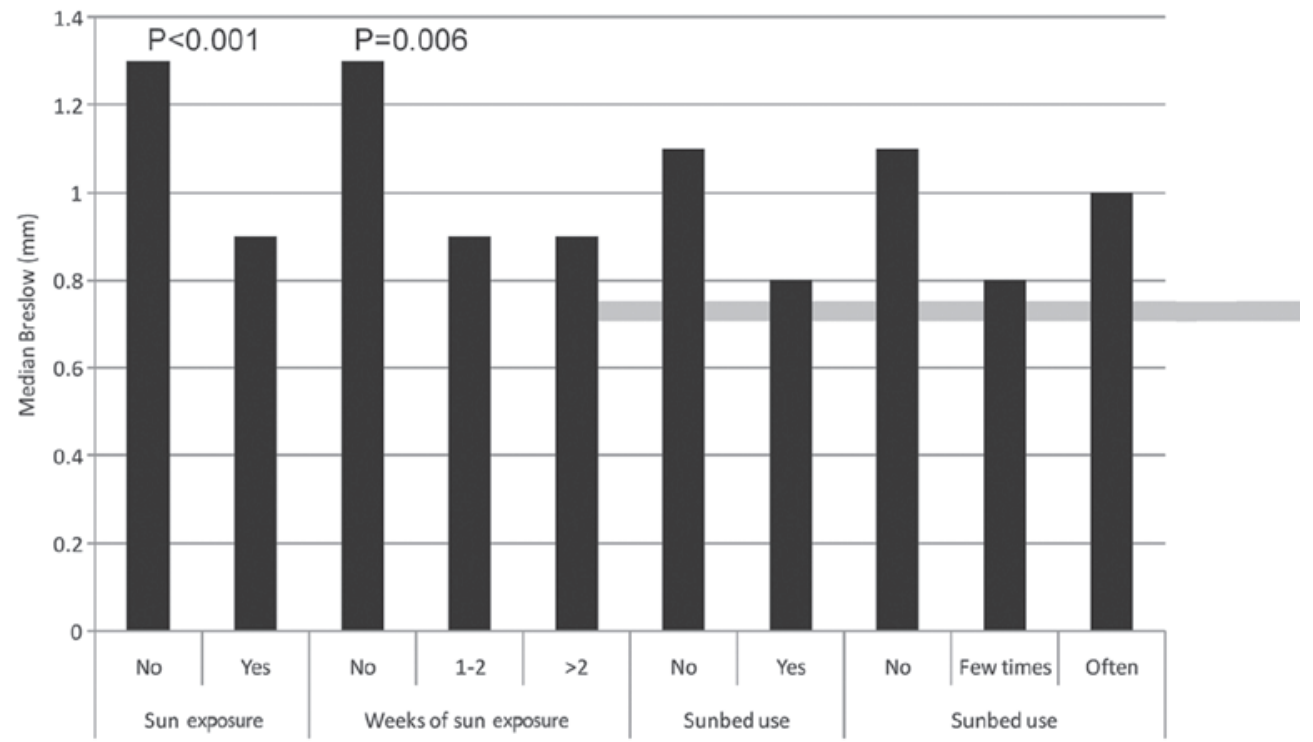

Figure 2. Median Breslow thickness by ultraviolet light exposure variables. P-values from fully adjusted mixed effect model, including age, gender, education, profession, body mass index and season of diagnosis.

thickness compared with women, younger patients and more educated patients (Table III). BMI was also independently identified to be significantly associated with Breslow thickness.

In a multivariate logistics model, evaluating the association with $>1 \mathrm{~mm}$ Breslow thickness, and adjusting for age, gender, residence, socioeconomic factors (education and profession), skin awareness/screening indicators (specialization of medical doctor performing the diagnosis and season of diagnosis) and BMI, holidays with sun exposure remained significantly associated with Breslow thickness ( $\mathrm{P}=0.01)$ (Table IV; Fig. 1), whereas sunbed use and exposure during peak hours of sunlight were not significantly associated with Breslow thickness. Similar results were obtained considering ulceration as a response variable; holidays with sun exposure remained significantly inversely associated with ulceration $(\mathrm{P}=0.009$; Table IV), as well as number of weeks of holidays with sun exposure ( $\mathrm{P}=0.011$; data not shown). 
Table II. Association between patient characteristics and holidays with sun exposure.

\begin{tabular}{|c|c|c|c|c|}
\hline Variable & Total & Holidays with sun exposure & Holidays with no sun exposure & P-value ${ }^{a}$ \\
\hline Total patients, $\mathrm{n}$ & $2673^{\mathrm{b}}$ & 1678 & 995 & \\
\hline Breslow thickness, n (\%) & & & & $<0.0001$ \\
\hline$<1 \mathrm{~mm}$ & $1329(50)$ & $902(54)$ & $427(43)$ & \\
\hline$\geq 1 \mathrm{~mm}$ & $1344(50)$ & $776(46)$ & $568(57)$ & \\
\hline Missing & 0 & 0 & 0 & \\
\hline Gender, n (\%) & & & & 0.29 \\
\hline Men & $1391(52)$ & $860(51)$ & $531(53)$ & \\
\hline Women & $1282(48)$ & $818(49)$ & $464(47)$ & \\
\hline Missing & 0 & 0 & 0 & \\
\hline Age, years, n (\%) & & & & $<0.0001$ \\
\hline$<55$ & $1351(51)$ & $1018(61)$ & $333(33)$ & \\
\hline$\geq 55$ & $1318(49)$ & $658(39)$ & $660(66)$ & \\
\hline Missing & 4 & 2 & 2 & \\
\hline Education level, n (\%) & & & & $<0.0001$ \\
\hline Low & $1046(39)$ & $501(30)$ & $545(55)$ & \\
\hline High & $1550(58)$ & $1140(68)$ & $410(41)$ & \\
\hline Missing & 77 & 37 & 40 & \\
\hline Profession level, n (\%) & & & & $<0.0001$ \\
\hline Low & $1507(56)$ & $848(51)$ & $659(66)$ & \\
\hline High & $1166(44)$ & $830(49)$ & $336(34)$ & \\
\hline Missing & 0 & 0 & 0 & \\
\hline Skin type ${ }^{\mathrm{c}}, \mathrm{n}(\%)$ & & & & 0.004 \\
\hline Dark & $1149(43)$ & $765(46)$ & $384(39)$ & \\
\hline Fair & $1523(57)$ & $913(54)$ & $610(61)$ & \\
\hline Missing & 1 & 0 & 1 & \\
\hline Season of diagnosis, $\mathrm{n}(\%)$ & & & & 0.217 \\
\hline Winter & $1269(47)$ & $818(49)$ & $451(45)$ & \\
\hline Summer & $694(26)$ & $422(25)$ & $272(27)$ & \\
\hline Autumn & $710(27)$ & $438(26)$ & $272(27)$ & \\
\hline Missing & 0 & 0 & 0 & \\
\hline Residence, n (\%) & & & & 0.0004 \\
\hline North & $1298(49)$ & $775(46)$ & $523(53)$ & \\
\hline Center & $296(11)$ & $218(13)$ & $78(8)$ & \\
\hline South & $1058(40)$ & $672(40)$ & $386(39)$ & \\
\hline Missing & 21 & 13 & 8 & \\
\hline Doctor specialty, n (\%) & & & & 0.0174 \\
\hline Oncologist & $1484(56)$ & $904(54)$ & $580(58)$ & \\
\hline Dermatologist & $774(29)$ & $503(30)$ & $271(27)$ & \\
\hline Other & $378(14)$ & $257(15)$ & $121(12)$ & \\
\hline Missing & 37 & 14 & 23 & \\
\hline Sunbed use, n (\%) & & & & $<0.0001$ \\
\hline None & $2253(84)$ & $1329(79)$ & $924(93)$ & \\
\hline Few & $338(13)$ & $280(17)$ & $58(6)$ & \\
\hline Often & $72(3)$ & $61(4)$ & $11(1)$ & \\
\hline Missing & 10 & 8 & 2 & \\
\hline Body mass index, $\mathrm{n}(\%)$ & & & & $<0.0001$ \\
\hline$<25$ & $1262(47)$ & $853(51)$ & $409(41)$ & \\
\hline$\geq 25$ & $1406(53)$ & $823(49)$ & $583(59)$ & \\
\hline Missing & 5 & 2 & 3 & \\
\hline
\end{tabular}

${ }^{\mathrm{a}} \chi^{2}$ test. ${ }^{\mathrm{b}}$ For 65 patients, sun exposure data was missing. ${ }^{\mathrm{c}}$ Fair' corresponds to stage I/II and 'Dark' to stage III/V Fitzpatrick skin type categories. 
Table III. Median Breslow thickness with patient features and results from multivariate random effects model.

\begin{tabular}{|c|c|c|c|c|c|}
\hline Variable & $\mathrm{n}$ & Median & Lower quartile & Upper quartile & P-value \\
\hline Overall & 2738 & 1.1 & 0.5 & 2.4 & \\
\hline Gender & & & & & 0.0002 \\
\hline Men & 1398 & 1.2 & 0.6 & 2.7 & \\
\hline Women & 1284 & 0.9 & 0.5 & 2.1 & \\
\hline Educational level $^{\mathrm{b}}$ & & & & & 0.005 \\
\hline Low & 1048 & 1.3 & 0.6 & 3.3 & \\
\hline High & 1553 & 0.9 & 0.5 & 1.9 & \\
\hline Professional level ${ }^{\mathrm{c}}$ & & & & & 0.012 \\
\hline No & 1572 & 1.2 & 0.6 & 2.8 & \\
\hline Yes & 1166 & 0.9 & 0.5 & 1.8 & \\
\hline Body mass index & & & & & 0.0008 \\
\hline$<25$ & 1265 & 0.8 & 0.5 & 2.0 & \\
\hline$\geq 25$ & 1412 & 1.2 & 0.6 & 3.0 & \\
\hline Age, years & & & & & $<0.0001$ \\
\hline$<55$ & 1360 & 0.8 & 0.5 & 1.7 & \\
\hline$\geq 55$ & 1327 & 1.3 & 0.6 & 3.4 & \\
\hline Season of diagnosis ${ }^{\mathrm{d}}$ & & & & & 0.002 \\
\hline Winter and spring & 1307 & 1.1 & 0.5 & 2.6 & \\
\hline Summer & 712 & 1.1 & 0.6 & 2.4 & \\
\hline Autumn & 719 & 0.9 & 0.5 & 2.0 & \\
\hline
\end{tabular}

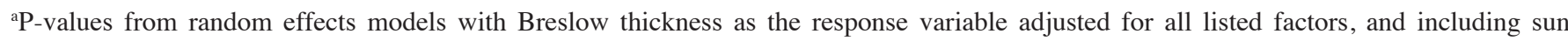
exposure. 'High school or higher degree were considered to represent 'high educational level', whereas lower degrees were categorized as 'low educational level'. 'Managers, freelancers and employees were considered to represent 'high professional level' and 'low professional level' included students, farmers, unemployed and housewives. ${ }^{\mathrm{d}}$ 'Summer’ included June, July and August, 'autumn’ included September, October and November and 'winter and spring' included from December to May.

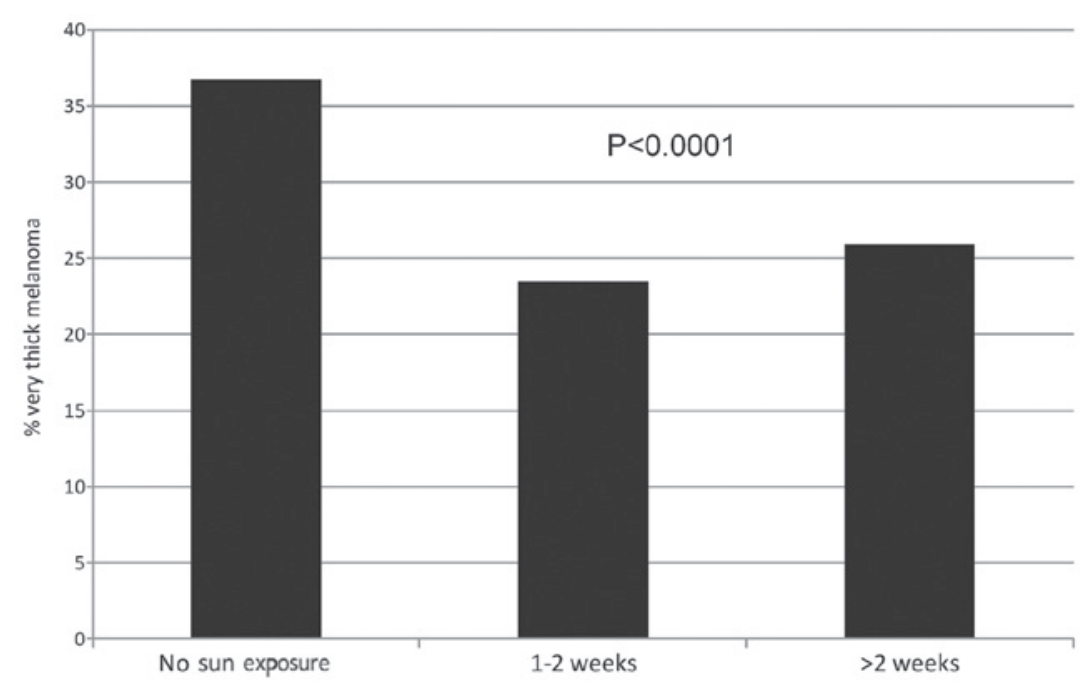

Figure 3. Frequencies of very thick melanoma (Breslow thickness, $>2 \mathrm{~mm}$ ) by number of weeks of holiday with sun exposure. P-value from logistic model adjusted for age, gender, body mass index, residence, season education, profession, degree of medical doctor and sunbed use.

Median Breslow thickness values are presented in Fig. 2 for a number of categorical variables that may be potentially associated with sun (or UV) exposure [holidays with sun exposure in the previous 5 years, sun exposure during peak hours of sunlight (11:00 a.m. to 1:00 p.m.), sunbed use and frequency of sunbed use]. Median thickness values were identified to be significantly lower among patients who took holidays with sun exposure. Random effects model analysis revealed that this difference remained significant following adjustment for confounding factors (including age, gender, 
Table IV. Results from multivariate logistic model for thick and ulcerated melanomas.

A, Results from multivariate logistic model for thick melanoma

\begin{tabular}{|c|c|c|c|c|}
\hline Variable & Category & Odds ratio & $95 \%$ confidence interval & P-value \\
\hline Holidays with sun exposure & Yes vs. no & 0.79 & $0.65-0.95$ & 0.014 \\
\hline Gender & Men vs. women & 1.26 & $1.06-1.50$ & 0.010 \\
\hline Age, years & $\geq 55$ vs. $<55$ & 1.58 & $1.31-1.90$ & $<0.0001$ \\
\hline Educational level & High vs. low & 0.74 & $0.61-0.89$ & 0.002 \\
\hline Professional level & High vs. low & 0.83 & $0.69-1.00$ & 0.048 \\
\hline Body mass index & $\geq 25$ vs. $<25$ & 1.34 & $1.12-1.59$ & 0.001 \\
\hline \multirow[t]{2}{*}{ Area of residence in Italy } & North vs. south & 0.52 & $0.43-0.62$ & 0.005 \\
\hline & Center vs. south & 0.45 & $0.33-0.62$ & 0.002 \\
\hline \multirow[t]{2}{*}{ Season of diagnosis } & Winter vs. autumn & 1.31 & $1.07-1.61$ & 0.054 \\
\hline & Summer vs. autumn & 1.25 & $0.99-1.56$ & 0.388 \\
\hline \multirow[t]{2}{*}{ Specialty of diagnosing doctor } & Oncologist vs. other & 0.91 & $0.71-1.17$ & 0.360 \\
\hline & Dermatologist vs. other & 0.70 & $0.53-0.93$ & 0.005 \\
\hline Sunbed use & Yes vs. no & 0.83 & $0.64-1.06$ & 0.132 \\
\hline Exposure during peak sunlight hours & Yes vs. no & 1.00 & $0.83-1.21$ & 0.979 \\
\hline
\end{tabular}

B, Results from multivariate logistic model for ulcerated melanoma

\begin{tabular}{|c|c|c|c|c|}
\hline Variable & Category & Odds ratio & $95 \%$ confidence interval & P-value \\
\hline Holidays with sun exposure & Yes vs. no & 0.76 & $0.61-0.93$ & 0.009 \\
\hline Gender & Men vs. women & 1.41 & $1.17-1.71$ & 0.0004 \\
\hline Age, years & $\geq 55$ vs. $<55$ & 1.47 & $1.19-1.81$ & 0.0003 \\
\hline Educational level & High vs. low & 0.70 & $0.57-0.85$ & 0.0004 \\
\hline \multirow[t]{2}{*}{ Area of residence in Italy } & North vs. south & 0.57 & $0.47-0.70$ & 0.157 \\
\hline & Center vs. south & 0.45 & $0.31-0.66$ & 0.004 \\
\hline \multirow[t]{2}{*}{ Specialty of diagnosing doctor } & Oncologist vs. other & 0.78 & $0.59-1.02$ & 0.413 \\
\hline & Dermatologist vs. other & 0.72 & $0.52-0.98$ & 0.093 \\
\hline Sunbed use & Yes vs. no & 0.77 & $0.56-1.06$ & 0.108 \\
\hline Exposure during peak sunlight hours & Yes vs. no & 0.97 & 0.78-1.19 & 0.739 \\
\hline
\end{tabular}

education, profession, BMI and season of diagnosis; $\mathrm{P}<0.001$ and $\mathrm{P}=0.006$ for holidays with sun exposure and weeks of holiday with sun exposure, respectively).

In Fig. 3, frequencies of very thick melanoma (Breslow thickness, $>2.0 \mathrm{~mm}$ ) are presented with the number of weeks of holiday with sun exposure. Frequencies of very thick melanoma were significantly lower in patients with a history of 1-2 weeks and $>2$ weeks of holiday with sun exposure compared with patients with no history of holidays with sun exposure in the 5 years prior to diagnosis $(\mathrm{P}<0.0001$, from multivariate logistic model adjusting for confounding variables).

\section{Discussion}

The present study of 2,738 melanoma patients suggested that holidays with sun exposure prior to diagnosis and number of weeks of holiday with sun exposure were significantly inversely associated with Breslow thickness and ulceration, whereas sunbed use and sun exposure during peak hours of sunlight were not identified to be associated with CM prognostic factors.
The analysis of skin awareness indicators (CM family history, visit to a dermatologist rather than a general medical doctor, diagnosis during summer and phenotype) was taken into account and results were confirmed. The present study additionally evaluated socioeconomic factors, as certain previous studies have demonstrated that low socioeconomic status may be significantly associated with the survival of melanoma patients (25). Previous holidays with sun exposure and number of weeks of holiday with sun exposure appear to be associated with a beneficial effect on disease status, in the form of less aggressive melanoma.

Solar radiation is a well-established skin carcinogen $(14,15)$, however, sun exposure is additionally the primary source of vitamin D. In a previous meta-analysis it was demonstrated that a continuous pattern of sun exposure was not a significant risk factor for melanoma, whereas intentional sun exposure and sunbed use were consistently associated with an increased risk (14). Furthermore, the results of the present study are in line with previous studies, suggesting a beneficial effect of sun exposure on melanoma patient survival (26) and overall survival (21). In an Italian 
population-based case-control study, multivariate models suggested an inverse association between holidays with sun exposure prior to diagnosis and melanoma-associated mortality, in a dose-dependent manner (27). An international population-based study of 3,578 melanoma cases revealed that a high recent UVB dose was associated with a significant $35 \%$ reduction in overall mortality (28).

One hypothesis is that the increased number of primarily thin melanoma cases and the decrease in recurrence may be associated with sun exposure, due to a potential link with vitamin D (29). It has been hypothesized that sun-associated vitamin $\mathrm{D}$ synthesis may have a beneficial effect on total mortality (16,30-32) and the incidence of certain types of cancer $(17,33)$. Additional observational studies identified an inverse association between vitamin D serum levels and melanoma prognosis $(31,32,34)$. However, the hypothetical role of vitamin D in the present study has been extrapolated by declared sun exposure, and such extrapolation should be performed with caution, particularly as sun exposure is a well-known risk factor for melanoma.

One novel hypothesis is that a percentage of the increase in the incidence of melanoma is comprised of non-life-threatening melanoma cases, which may be promoted by sun exposure $(35,36)$. Intense recent sun exposure may be able to trigger melanoma with little malignant potential. If this is true, then there is a requirement to develop an improved understanding of what triggers aggressive melanoma.

Population-based registries with clinical data on melanoma are few in Italy, and the Clinical National Melanoma Registry (CNMR) does not have the typical aim of cancer registries to estimate incidence data. The registry is a multi-center collection of clinical and epidemiological data, with the aim of improving collaboration between hospitals and research centers in order to obtain homogeneous data collection of epidemiological and clinical data on a large data scale. Being able to increase the statistical power and obtain homogeneous data, particularly for a rare disease like melanoma, is important when the aim is to evaluate associations between melanoma prognostic factors and epidemiological and clinical data, taking into account multiple confounding variables. CNMR is not a tumor registry and it does not possess the aim of estimating Italian melanoma incidence rates; however, the data are comparable with results identified in population-based tumor registries, for example, significantly higher Breslow thickness values were observed at an advanced age, among men and among patients of higher socioeconomic levels (37).

Even if the present study adjusted for educational and professional level, it may be supposed that the association with holidays with sun exposure may remain confounded by socioeconomic factors that are not easily recorded. For example, the present study did not record data on salary and economic factors, as well as information on lifestyle factors and changes in profession over time. Furthermore, melanoma cases in highly educated individuals may be diagnosed at a thinner stage due to more frequent skin screening and increased access to medical doctors; however, thinner melanomas may additionally be occurring at an increased rate in the more affluent population that are able to travel and take holidays abroad. However, holidays with sun exposure remained significantly associated with
Breslow thickness and ulceration following adjustment for level of education and skin awareness indicators.

In conclusion, additional efforts are necessary to improve public and medical education concerning early detection and prompt surgical treatment, which is known to be the most effective treatment modality for CM. Men of a lower educational level should be the focus of future prevention campaigns, and this may be achieved by promoting more frequent full body skin examinations for older men. Investigation of the hypothesis of a possible role of vitamin D in melanoma survival in a clinical trial setting has the potential to be an interesting and useful future research area $(38,39)$.

\section{Acknowledgements}

The CNMR was supported by grants received from Bristol Myers Squibb (New York, NY, USA) and GlaxoSmithKline (Brentford, UK) and the authors would like to thank the Intergruppo Melanoma Italiano.

\section{References}

1. Ferlay J, Shin HR, Bray F, Forman D, Mathers C and Parkin DM: Estimates of worldwide burden of cancer in 2008: GLOBOCAN 2008. Int J Cancer 127: 2893-2917, 2010.

2. Tryggvadóttir L, Gislum M, Hakulinen T, Klint A, Engholm G, Storm $\mathrm{HH}$ and Bray F: Trends in the survival of patients diagnosed with malignant melanoma of the skin in the Nordic countries 1964-2003 followed up to the end of 2006. Acta Oncol 49: 665-672, 2010.

3. Hollestein LM, de Vries E and Nijsten T: Trends of cutaneous squamous cell carcinoma in the Netherlands: Increased incidence rates, but stable relative survival and mortality 1989-2008. Eur J Cancer 48: 2046-2053, 2012.

4. de Vries E, Bray FI, Coebergh JW and Parkin DM: Changing epidemiology of malignant cutaneous melanoma in Europe 1953-1997: Rising trends in incidence and mortality but recent stabilizations in western Europe and decreases in Scandinavia. Int J Cancer 107: 119-126, 2003.

5. Garbe $\mathrm{C}$ and Leiter U: Melanoma epidemiology and trends. Clin Dermatol 27: 3-9, 2009.

6. Qin J, Berwick M, Ashbolt R and Dwyer T: Quantifying the change of melanoma incidence by Breslow thickness. Biometrics 58: 665-670, 2002.

7. Lipsker D, Engel F, Cribier B, Velten M and Hedelin G: Trends in melanoma epidemiology suggest three different types of melanoma. Br J Dermatol 157: 338-343, 2007.

8. Erdmann F, Lortet-Tieulent J, Schüz J, Zeeb H, Greinert R, Breitbart EW and Bray F: International trends in the incidence of malignant melanoma 1953-2008 - are recent generations at higher or lower risk? Int J Cancer 132: 385-400, 2013.

9. Coory M, Baade P, Aitken J, Smithers M, McLeod GR and Ring I: Trends for in situ and invasive melanoma in Queensland, Australia, 1982-2002. Cancer Causes Control 17: 21-27, 2006.

10. Jemal A, Saraiya M, Patel P, Cherala SS, Barnholtz-Sloan J, Kim J, Wiggins CL and Wingo PA: Recent trends in cutaneous melanoma incidence and death rates in the United States, 1992-2006. J Am Acad Dermatol 65: S17-S25, 2011.

11. MacKie RM, Bray C, Vestey J, Doherty V, Evans A, Thomson D and Nicolson M; Scottish Melanoma Group: Melanoma incidence and mortality in Scotland 1979-2003. Br J Cancer 96: 1772-1777, 2007.

12. de Vries E, Schouten LJ, Visser O, Eggermont AM and Coebergh JW; Working Group of Regional Cancer Registries: Rising trends in the incidence of and mortality from cutaneous melanoma in the Netherlands: A Northwest to Southeast gradient? Eur J Cancer 39: 1439-1446, 2003.

13. Anderson WF, Pfeiffer RM, Tucker MA and Rosenberg PS: Divergent cancer pathways for early-onset and late-onset cutaneous malignant melanoma. Cancer 115: 4176-4185, 2009.

14. Gandini S, Sera F, Cattaruzza MS, Pasquini P, Picconi O, Boyle P and Melchi CF: Meta-analysis of risk factors for cutaneous melanoma: II. Sun exposure. Eur J Cancer 41: 45-60, 2005. 
15. El Ghissassi F, Baan R, Straif K, Grosse Y, Secretan B, Bouvard V, Benbrahim-Tallaa L, Guha N, Freeman C, Galichet L, and Cogliano V; WHO International Agency for Research on Cancer Monograph Working Group: A review of human carcinogens - part D: Radiation. Lancet Oncol 10: 751-752, 2009.

16. Zittermann A, Iodice S, Pilz S, Grant WB, Bagnardi V and Gandini S: Vitamin D deficiency and mortality risk in the general population: A meta-analysis of prospective cohort studies. Am J Clin Nutr 95: 91-100, 2012.

17. Gandini S, Boniol M, Haukka J, Byrnes G, Cox B, Sneyd MJ, Mullie P and Autier P: Meta-analysis of observational studies of serum 25-hydroxyvitamin D levels and colorectal, breast and prostate cancer and colorectal adenoma. Int J Cancer 128: $1414-1424,2011$

18. Gandini S, Raimondi S, Gnagnarella P, Doré JF, Maisonneuve P and Testori A: Vitamin D and skin cancer: A meta-analysis. Eur J Cancer 45: 634-641, 2009.

19. Gnagnarella P, Pasquali E, Serrano D, Raimondi S, Disalvatore D and Gandini S: Vitamin D receptor polymorphism FokI and cancer risk: A comprehensive meta-analysis. Carcinogenesis 35: 1913-1919, 2014

20. Boniol M, Autier P, Boyle P and Gandini S: Cutaneous melanoma attributable to sunbed use: Systematic review and meta-analysis. BMJ 345: e4757, 2012.

21. Berwick M, Armstrong BK, Ben-Porat L, Fine J, Kricker A, Eberle $\mathrm{C}$ and Barnhill R: Sun exposure and mortality from melanoma. J Natl Cancer Inst 97: 195-199, 2005.

22. Yang L, Lof M, Veierød MB, Sandin S, Adami HO and Weiderpass E: Ultraviolet exposure and mortality among women in Sweden. Cancer Epidemiol Biomarkers Prev 20: 683-690, 2011.

23. US Food and Drug Administration: US Food and Drug Administration-21 CFR Part 11: Electronic Records; Electronic Signatures. http://www.accessdata.fda. gov/scripts/cdrh/cfdocs/cfefr/CFRSearch.cfm?CFRPart=11. Accessed May 28, 2008.

24. Fitzpatrick TB: The validity and practicality of sun-reactive skin types I through VI. Arch Dermatol 124: 869-871, 1988.

25. Gandini S,De Vries E, Tosti G,BotteriE,Spadola G,MaisonneuveP, Martinoli C, Joosse A, Ferrucci PF, Baldini F, et al: Sunny holidays before and after melanoma diagnosis are respectively associated with lower Breslow thickness and lower relapse rates in Italy. PLoS One 8: e78820, 2013

26. Mandalá M, Imberti GL, Piazzalunga D, Belfiglio M, Lucisano G Labianca R, Marchesi L, Merelli B, Robone S, Poletti P, et al: Association of socioeconomic status with Breslow thickness and disease-free and overall survival in stage I-II primary cutaneous melanoma. Mayo Clin Proc 86: 113-119, 2011.
27. Rosso S, Sera F, Segnan N and Zanetti R: Sun exposure prior to diagnosis is associated with improved survival in melanoma patients: Results from a long-term follow-up study of Italian patients. Eur J Cancer 44: 1275-1281, 2008.

28. Berwick M, Reiner AS, Paine S, Armstrong BK, Kricker A, Goumas C, Cust AE, Thomas NE, Groben PA, From L, et al: Sun exposure and melanoma survival: A GEM study. Cancer Epidemiol Biomarkers Prev 23: 2145-2152, 2014

29. Egan KM, Sosman JA and Blot WJ: Sunlight and reduced risk of cancer: Is the real story vitamin D? J Natl Cancer Inst 97: 161-163, 2005.

30. Autier P and Gandini S: Vitamin D supplementation and total mortality: A meta-analysis of randomized controlled trials. Arch Intern Med 167: 1730-1737, 2007.

31. Randerson-Moor JA, Taylor JC, Elliott F, Chang YM, Beswick S, Kukalizch K, Affleck P, Leake S, Haynes S, Karpavicius B, et al: Vitamin $\mathrm{D}$ receptor gene polymorphisms, serum 25-hydroxyvitamin D levels, and melanoma: UK case-control comparisons and a meta-analysis of published VDR data. Eur J Cancer 45: 3271-3281, 2009.

32. Newton-Bishop J, Beswick S, Jackon S, Renderson Moor J, Elliott F, Barrett J, Affleck P, Marsden J and Bishop T: Vitamin $\mathrm{D}$ and survival from melanoma. Melanoma Res 16, S26-S27, 2006.

33. Raimondi S, Johansson H, Maisonneuve P and Gandini S: Review and meta-analysis on vitamin $\mathrm{D}$ receptor polymorphisms and cancer risk. Carcinogenesis 30: 1170-1180, 2009.

34. Newton-Bishop JA, Beswick S, Randerson-Moor J, Chang YM, Affleck P, Elliott F, Chan M, Leake S, Karpavicius B, Haynes S, et al: Serum 25-hydroxyvitamin D3 levels are associated with breslow thickness at presentation and survival from melanoma. J Clin Oncol 27: 5439-5444, 2009.

35. Gilchrest BA, Eller MS, Geller AC and Yaar M: The pathogenesis of melanoma induced by ultraviolet radiation. N Engl J Med 340: 1341-1348, 1999

36. Berwick M, Armstrong BK, Ben-Porat L, Fine J, Kricker A, Eberle $\mathrm{C}$ and Barnhill R: Sun exposure and mortality from melanoma. J Natl Cancer Inst 97: 195-199, 2005.

37. Ambrosini-Spaltro A, Dal Cappello T, Deluca J, Carriere C, Mazzoleni G and Eisendle K: Melanoma incidence and Breslow tumour thickness development in the central Alpine region of South Tyrol from 1998 to 2012: A population-based study. J Eur Acad Dermatol Venereol 29: 243-248, 2015.

38. Guerrieri-Gonzaga A and Gandini S: Vitamin D and overall mortality. Pigment Cell Melanoma Res 26: 16-28, 2013.

39. Gandini S, Francesco F, Johanson H, Bonanni B and Testori A: Why vitamin D for cancer patients? Ecancermedicalscience 3: $160,2009$. 